\title{
PREGNANCY COMPLICATIONS AND DELIVERY OUTCOMES OF PREGNANT WOMEN WITH COMMON COLD
}

\author{
Ferenc Bánhidy ${ }^{1}$, Nándor Ács ${ }^{1}$, Erzsébet Puhóz, ${ }^{2,3}$, Andrew E. Czeizel ${ }^{2}$ \\ ${ }^{1}$ Second Department of Obstetrics and Gynecology, Semmelweis University, School of Medicine, Budapest, Hungary \\ ${ }^{2}$ Foundation for the Community Control of Hereditary Diseases, Budapest, Hungary \\ ${ }^{3}$ Department of Human Genetics and Teratology, National Center for Epidemiology, Budapest, Hungary
}

\begin{abstract}
SUMMARY
Objective: To study the association between common cold during pregnancy and pregnancy complications and delivery outcomes: gestational age/birth weight, in addition preterm birth and low birthweight.

Method: In the population-based large data set of the Hungarian Case-Control Surveillance System of Congenital Abnormalities (HCCSCA), 19801996, controls without congenital abnormalities were analysed.

Results: Of 38,151 newborn infants, 5,475 (14.4\%) had mothers with common cold. The prevalence of threatened preterm delivery, placental disorders and severe nausea and vomiting was lower while the occurrence of anemia was higher in pregnant mothers with common cold than in mothers without common cold. Mothers with common cold in pregnancy had 0.1 week shorter gestational age, thus the proportion of preterm births $(9.8 \%$ vs $9.1 \%)$ was somewhat larger. However, mean birth weight was somewhat larger (3,305 vs 3,271 g) and the proportion of low birthweight newborns $(4.2 \%$ vs $5.9 \%)$ was smaller.

Conclusion: Common cold during pregnancy does not increase the occurrence of pregnancy complications except anemia, while delivery outcomes showed minor but opposite (higher rate of preterm birth and lower rate of low birthweight) changes.
\end{abstract}

Key words: common cold, pregnancy, pregnancy complications, gestational age, birth weight

Address for correspondence: A. E. Czeizel, 1026 Budapest, Törökvész lejtö 32, Hungary, E-mail: czeizel@interware.hu

\section{INTRODUCTION}

The common cold is a conventional term for a mild upper respiratory illness caused by different microorganisms mainly from the virus family of picornaviridae (rhinoviruses, echoviruses, coxsackie viruses), influenza, parainfluenza, metapneumovirus, adeno- and respiratory syncytial viruses (1). The common cold is manifested such as acute coryza or nasopharyngitis with the symptoms of nasal stuffiness and discharge, sneezing, sore throat, and cough, in general without fever (2). However, common cold is frequently followed by secondary complications including fever.

The common cold is the most frequently reported maternal disorder during pregnancy in Hungary, nevertheless as far as we know so far the effects of common cold during pregnancy have not been studied for pregnancy complications and delivery outcomes. The large and population-based data set of the Hungarian Case-Control Surveillance of Congenital Abnormalities (HCCSCA) (3) seemed to be appropriate for the study of pregnancy complications and delivery outcomes such as birth weight and gestational age, in addition to the proportion of low birthweight and preterm birth as indicators of fetal development in the control newborn infants without any defect born to mothers with or without common cold.

\section{METHODS}

Newborn infants without congenital abnormalities were selected from the National Birth Registry of the Central Statistical Office as controls for the HCCSCA. Cases with congenital abnormality were identified in the Hungarian Congenital Abnormality Registry (4) for the HCCSCA. In general, two controls without defect were matched to every case according to sex, week of birth and district of parents' residence of cases. If selected controls were twins, only one of them was randomly included to the data set of the HCCSCA. Here the data of pregnancy complications and delivery outcomes are evaluated only in the control newborn infants without any birth defects because congenital abnormalities may have a more drastic effect for these variables than common cold.

The data on pregnancy complications and delivery outcomes, in addition to confounders such as demographic data of mothers, use of medicinal products (drugs and pregnancy supplements), maternal diseases including common cold were obtained from three sources of information: 1. Prospective data through prenatal care logbooks and other medical records, particularly discharge summaries before the birth of babies. Prenatal care was mandatory for pregnant women in Hungary (if somebody did not visit prenatal care, she did not get maternity grant and leave), thus 
nearly $100 \%$ of pregnant women visited prenatal care, on average 7 times during the study period. The first visit was between the $6^{\text {th }}$ and $12^{\text {th }}$ gestational week. Licensed obstetricians were obliged to record all pregnancy complications, maternal diseases and related drug prescriptions in the logbook. 2. Retrospective data by a structured questionnaire completed by mothers after the birth of newborn infants. The time between the end of pregnancy and return of questionnaire was $5.2 \pm 2.9$ months. 3 . In addition, 200 non-respondent mothers were visited and questioned at home as part of a validation study (5). Information was available on $83.0 \%$ of mothers ( $82.6 \%$ from reply, $0.4 \%$ from visit). Prenatal care logbook was available in $93.8 \%$ of mothers.

The diagnosis of common cold was based on the reported data, but two groups with or without antifever drug treatments were differentiated. Pregnancy complications were recorded in the prenatal care logbook. Both birth weight and gestational age were medically recorded in the discharge summary of delivery. We calculated gestational age from the first day of the last menstrual period. The definition of preterm birth was less than 37 completed weeks (less than 259 days), while postterm birth was 42 completed weeks or more (i.e. 294 days or more). Thus term births occurred from 37 to less than 42 completed weeks (259 to 293 days). On the other hand, low (less than $2500 \mathrm{~g}$ ) and large (more than $4500 \mathrm{~g}$ ) birth weight were also evaluated.

Here only the 17 years' data set of the HCCSCA (1980-1996) are evaluated because the method of data collection was changed after 1996. The details of the HCCSCA's methods have been described previously $(3,6)$.

\section{Statistical Analysis of Data}

Statistical analyses were carried-out with the software SAS version 8.02 (SAS Institute Ins., Cary, North Carolina, USA). We calculated prevalence odds ratios (POR) and their 95\% confidence intervals (CI) for categorical data, while Student t-test for quantitative variables. Employment status was exceptional because $\chi^{2}$ test was used for the evaluation of subgroups. At the calculation of adjusted $t$ and POR, maternal age, birth order, employment status as indicator of socioeconomic status, antifever drugs and pregnancy supplements were used as confounders.

\section{RESULTS}

The number of births was 2,146,574 in Hungary during the study period. We sampled 38,151 of these births without any congenital abnormalities, representing $1.8 \%$ of Hungarian births during the study period. Of the 38,151 newborn infants, 5,475 ( $14.4 \%$ ) had mothers with common cold. Of 5,475 pregnant women, 2,699 (49.3\%) had medically recorded common cold.

The usual duration of common cold (nasopharyngitis) was one week without secondary complications. However, about half of our pregnant women had a longer duration due to secondary complications including sinusitis, otitis media, laryngitis, tracheitis, bronchitis, etc., and in general these mothers had antifever therapy.

The monthly distribution of common cold showed a higher occurrence between October and February with a peak in December (Table 1). However, common cold occurred in other months as well while influenza was recorded only between December and
April. The monthly occurrence of acute infectious diseases of respiratory system showed some similarities with common cold but their distribution statistically was different (Table 1).

Common cold was diagnosed in all gestational months of the study pregnancy, however, its prevalence was high in the first seven gestational months $(10.2,11.7,16.0,15.0,13.9,10.7$ and $11.2 \%)$, and lower in the $8^{\text {th }}(7.7 \%)$ and particularly low in the $9^{\text {th }}(3.7 \%)$ month of gestation.

Table 1. The onset of common cold, in addition of influenza and acute infectious diseases of respiratory system without common cold according to month in mothers of newborn infants studied

\begin{tabular}{|l|l|l|l|l|l|l|}
\hline Month & \multicolumn{2}{|l|}{ Common cold } & \multicolumn{2}{|c|}{ Influenza } & \multicolumn{2}{|c|}{$\begin{array}{c}\text { Acute } \\
\text { infections } \\
\text { of respiratory } \\
\text { system }\end{array}$} \\
\hline & No. & $\%$ & No. & $\%$ & No. & $\%$ \\
\hline January & 591 & 10.8 & 389 & 21.2 & 419 & 12.1 \\
\hline February & 546 & 10.0 & 386 & 21.0 & 409 & 11.8 \\
\hline March & 417 & 7.6 & 385 & 21.0 & 327 & 9.5 \\
\hline April & 334 & 6.1 & 226 & 12.3 & 262 & 7.6 \\
\hline May & 327 & 6.0 & 0 & 0.0 & 201 & 5.8 \\
\hline June & 282 & 5.2 & 0 & 0.0 & 188 & 5.4 \\
\hline July & 220 & 4.0 & 0 & 0.0 & 156 & 4.5 \\
\hline August & 281 & 5.1 & 0 & 0.0 & 162 & 4.7 \\
\hline September & 368 & 6.7 & 0 & 0.0 & 212 & 6.1 \\
\hline October & 488 & 8.9 & 0 & 0.0 & 270 & 7.8 \\
\hline November & 655 & 12.0 & 0 & 0.0 & 307 & 8.9 \\
\hline December & 966 & 17.6 & 452 & 24.5 & 542 & 15.7 \\
\hline Total & 5,475 & 100.0 & 1,838 & 100.0 & 3,455 & 100.0 \\
\hline Comparison & referent & $\begin{array}{l}\chi_{11}^{2}=1447.8 \\
p<0.0001\end{array}$ & $\begin{array}{c}\chi_{11}^{2}=55.9 \\
p<0.0001\end{array}$ \\
\hline
\end{tabular}

*without common cold

Table 2 summarizes potential confounders in mothers with common cold or without common cold as referent. Both mean maternal age and birth order was somewhat lower in mothers with common cold, than in mothers without common cold. The proportion of unmarried women was smaller in mothers with common cold. There was some difference in the distributrion of maternal employment status, the proportion of professionals and managerials was larger, while the proportion of semi- and unskilled workers, in addition of housewives was smaller in mothers with common cold. In Hungary most housewives belong to the low socioeconomic status.

The mothers of 1,714 (31.3\%) newborn infants had only common cold during pregnancy. Among acute infectious maternal disorders during pregnancy (Table 2), the diseases of respiratory and digestive systems showed a higher prevalence in mothers with common cold. The higher occurrence of other acute diseases was 
Table 2. Basic characteristics of mothers with or without common cold

\begin{tabular}{|c|c|c|c|c|c|c|}
\hline \multirow[t]{2}{*}{ Maternal confounders } & \multicolumn{2}{|c|}{$\begin{array}{l}\text { With common cold } \\
(\mathrm{N}=5,475)\end{array}$} & \multicolumn{2}{|c|}{$\begin{array}{l}\text { Without common cold } \\
\qquad(\mathrm{N}=32,676)\end{array}$} & \multirow{2}{*}{\multicolumn{2}{|c|}{ Comparison }} \\
\hline & No. & $\%$ & No. & $\%$ & & \\
\hline \multicolumn{7}{|l|}{ Maternal age (yr) } \\
\hline$<25$ & 2,676 & 48.9 & 15,318 & 46.9 & \multirow{3}{*}{\multicolumn{2}{|c|}{$\begin{array}{l}x_{2}^{2}=88.2 \\
p<0.0001\end{array}$}} \\
\hline $25-29$ & 2,004 & 36.6 & 10,881 & 33.3 & & \\
\hline$>29$ & 795 & 14.5 & 6,477 & 19.8 & & \\
\hline Mean (S.D.) & \multicolumn{2}{|c|}{$25.1 \pm 4.4$} & \multicolumn{2}{|c|}{$25.5 \pm 4.9$} & $t=7.0$ & $p<0.0001$ \\
\hline \multicolumn{7}{|l|}{ Birth order } \\
\hline 1 & 2,851 & 52.1 & 15,358 & 47.0 & \multirow{2}{*}{\multicolumn{2}{|c|}{$\begin{array}{l}x_{1}^{2}=48.3 \\
p<0.0001\end{array}$}} \\
\hline$\geq 2$ & 2,624 & 47.9 & 17,318 & 53.0 & & \\
\hline Mean (S.D.) & \multicolumn{2}{|c|}{$1.6 \pm 0.9$} & \multicolumn{2}{|c|}{$1.7 \pm 0.9$} & $\mathrm{t}=10.0$ & $p<0.0001$ \\
\hline Unmarried & 153 & 2.8 & 1,318 & 4.0 & $X_{1}^{2}=19.4$ & $p<0.001$ \\
\hline \multicolumn{7}{|l|}{ Employment status } \\
\hline Professionals & 813 & 14.9 & 3,540 & 10.8 & \multirow{7}{*}{\multicolumn{2}{|c|}{$\begin{array}{l}X_{6}^{2}=185.6 \\
p<0.0001\end{array}$}} \\
\hline Managerial & 1,576 & 28.8 & 8,558 & 26.2 & & \\
\hline Skilled worker & 1,720 & 31.4 & 9,970 & 30.5 & & \\
\hline Semiskilled worker & 685 & 12.5 & 5,098 & 15.6 & & \\
\hline Unskilled worker & 193 & 3.5 & 1,666 & 5.1 & & \\
\hline Housewife & 179 & 3.3 & 1,859 & 5.7 & & \\
\hline Others & 309 & 5.6 & 1,985 & 6.1 & & \\
\hline Acute infectious diseases & & & & & POR & $95 \% \mathrm{Cl}$ \\
\hline Influenza & 251 & 4.6 & 1,587 & 4.9 & 0.9 & $0.8-1.1$ \\
\hline Respiratory system & 803 & 14.7 & 2,652 & 8.1 & 1.9 & $1.8-2.1$ \\
\hline Digestive system & 222 & 4.1 & 717 & 2.2 & 1.9 & $1.6-2.2$ \\
\hline Urinary tract & 339 & 6.2 & 1,962 & 6.0 & 1.0 & $0.9-1.2$ \\
\hline Genital organs & 412 & 7.5 & 2,479 & 7.6 & 1.0 & $0.9-1.1$ \\
\hline Others & 116 & 2.1 & 396 & 1.2 & 1.8 & $1.4-2.2$ \\
\hline \multicolumn{7}{|l|}{ Chronic diseases } \\
\hline Diabetes mellitus & 10 & 0.2 & 42 & 0.1 & 1.4 & $0.7-2.8$ \\
\hline Epilepsy & 9 & 0.2 & 68 & 0.2 & 0.8 & $0.4-1.6$ \\
\hline Others & 1,087 & 19.9 & 5,528 & 16.9 & 1.2 & $1.1-1.3$ \\
\hline \multicolumn{7}{|l|}{ Frequently used drugs } \\
\hline Acetylsalicylic acid & 719 & 13.1 & 785 & 2.4 & 6.1 & $5.5-6.8$ \\
\hline Allylestrenol & 896 & 16.4 & 4,461 & 13.7 & 1.2 & $1.1-1.3$ \\
\hline Aminophylline & 285 & 5.2 & 1,999 & 6.1 & 0.8 & $0.7-0.9$ \\
\hline Ampicillin & 626 & 11.4 & 2,004 & 6.1 & 2.0 & $1.8-2.2$ \\
\hline Bromhexine & 280 & 5.1 & 520 & 1.6 & 3.3 & $2.9-3.9$ \\
\hline Clotrimazole & 558 & 10.2 & 2,519 & 7.7 & 1.4 & $1.2-1.5$ \\
\hline Diazepam & 605 & 11.1 & 3,525 & 10.8 & 1.0 & $0.9-1.1$ \\
\hline Dimenhydrinate & 318 & 5.8 & 1,408 & 4.3 & 1.4 & $1.2-1.6$ \\
\hline Drotaverine & 528 & 9.6 & 2,953 & 9.0 & 1.1 & $0.9-1.2$ \\
\hline Magnesiums & 287 & 5.2 & 1,663 & 5.1 & 1.0 & $0.9-1.2$ \\
\hline Metamizole & 572 & 10.5 & 1,339 & 4.1 & 2.7 & $2.5-3.0$ \\
\hline Penamecillin & 859 & 15.7 & 1,387 & 4.2 & 4.2 & $3.8-4.6$ \\
\hline Promethazine & 904 & 16.5 & 5,121 & 15.7 & 1.1 & $0.9-1.2$ \\
\hline Terbutalin & 583 & 10.7 & 3,411 & 10.4 & 1.0 & $0.9-1.1$ \\
\hline \multicolumn{7}{|l|}{ Pregnancy supplements } \\
\hline Iron & 3,751 & 68.5 & 23,023 & 70.5 & 0.9 & $0.9-1.0$ \\
\hline Calcium & 620 & 11.3 & 2,963 & 9.1 & 1.3 & $1.2-1.4$ \\
\hline Folic acid & 2,851 & 52.1 & 17,924 & 54.9 & 0.9 & $0.8-1.0$ \\
\hline Vitamin $B_{6}$ & 602 & 11.0 & 3,484 & 10.7 & 1.0 & $0.9-1.1$ \\
\hline Vitamin D & 1,142 & 20.9 & 9,008 & 27.6 & 0.7 & $0.6-0.7$ \\
\hline Vitamin C & 319 & 5.8 & 1,359 & 4.2 & 1.4 & $1.3-1.6$ \\
\hline Vitamin E & 239 & 4.4 & 2,048 & 6.3 & 0.7 & $0.6-0.8$ \\
\hline Others or unspecified vitamins & 967 & 17.7 & 3,709 & 11.4 & 1.7 & $1.6-1.8$ \\
\hline Multivitamins & 387 & 7.1 & 2,122 & 6.5 & 1.1 & $0.9-1.2$ \\
\hline
\end{tabular}


Table 3. Prevalence of pregnancy complications in pregnant women with or without common cold

\begin{tabular}{|c|c|c|c|c|c|}
\hline \multirow{2}{*}{ Pregnancy complications } & \multicolumn{2}{|c|}{$\begin{array}{l}\text { With common cold } \\
\quad(N=5,475)\end{array}$} & \multicolumn{2}{|c|}{$\begin{array}{l}\text { Without common cold } \\
\qquad(\mathrm{N}=32,676)\end{array}$} & \multirow{2}{*}{$\begin{array}{c}\text { Difference } \\
\text { POR }(95 \% \mathrm{Cl})\end{array}$} \\
\hline & No. & $\%$ & No. & $\%$ & \\
\hline Threatened abortion & 888 & 16.2 & 5,624 & 17.2 & $0.93(0.86-1.01)$ \\
\hline Placental disorders* & 65 & 1.2 & 527 & 1.6 & $0.73(0.57-0.95)$ \\
\hline Nausea and vomiting, severe & 499 & 9.1 & 3,370 & 10.3 & $0.87(0.79-0.96)$ \\
\hline Threatened preterm delivery ${ }^{* \star}$ & 569 & 10.4 & 4,891 & 15.0 & $0.66(0.60-0.72)$ \\
\hline Preeclampsia*** & 457 & 8.4 & 2,764 & 8.5 & $0.99(0.89-1.09)$ \\
\hline Prolonged pregnancy & 82 & 1.5 & 426 & 1.3 & $1.15(0.91-1.46)$ \\
\hline Gestational diabetes & 28 & 0.5 & 242 & 0.7 & $0.69(0.47-1.02)$ \\
\hline Polyhydramnios & 32 & 0.6 & 159 & 0.5 & $1.20(0.82-1.76)$ \\
\hline Oligohydramnios & 1 & 0.0 & 13 & 0.0 & $0.46(0.06-3.51)$ \\
\hline Anemia & 1,036 & 18.9 & 5,320 & 16.3 & $1.20(1.12-1.29)$ \\
\hline
\end{tabular}

* including placenta previa, premature separation of placenta, antepartum hemorrhage

** including cervical incompetence

*** including pregnancy hypertension, albuminuria and oedema

explained mainly by otitis media which might be connected with common cold. The prevalence of chronic maternal disorders was similar in pregnant women with or without common cold, except the "others" including very heterogeneous diseases.

Among medicinal products, frequently used drugs and pregnancy supplements were differentiated (Table 2). Two antifever (acetylsalicylic acid and metamizole) and three antimicrobial (ampicillin, clotrimazol, penamecillin) drugs were used more frequently by mothers with common cold. The use of allylestrenol, bromhexine and dimenhydrinate connected with pregnancy complications was also more frequent in mothers with common cold.

There was a higher use of calciums and vitamin $\mathrm{C}$, while a lower use of vitamin $\mathrm{D}$ and $\mathrm{E}$ in the mothers with common cold.

The first objective of our study was the evaluation of pregnancy complications (Table 3). The proportion of anemia was larger while of severe nausea and vomiting, placental disorders, and particularly threatened preterm delivery was smaller in mothers with common cold than in the mothers without common cold.

Sex ratio, i.e. the proportion of boys was similar in the newborns of mothers with common cold $(3,526 ; 64.4 \%)$ compared to the group of mothers without common cold $(21,273 ; 65.1 \%)$ $\left(\chi_{1}^{2}=1.0 ; \mathrm{p}=0.31\right)$.

The second objective of the study, i.e. the evaluation of delivery outcomes was based on gestational age and birth weight (Table 4). Mean gestational age was 0.1 week shorter in the mothers with common cold compared with mothers without common cold. However, the mean birth weight was $34 \mathrm{~g}$ larger in liveborn babies born to mothers with common cold than in the newborns of mothers without common cold. Adjusted POR for the rate of preterm births $(9.8 \%$ vs $9.1 \%)$ showed a significant increase, while the proportion of low birthweight ( $4.2 \%$ vs. $5.9 \%)$ was smaller in the group of mothers with common cold compared with newborn infants born to mothers without common cold. There was no obvious difference in the proportion of postterm birth and large birthweight.

Finally we differentiated newborn infants born to mothers with common cold according to antifever therapy because we supposed that pregnant women with antifever therapy had secondary complications including fever. However, there was no obvious difference in delivery outcomes between the two study groups.

\section{DISCUSSION}

Our study showed a lower prevalence of threatened preterm delivery, placental disorders, and severe nausea and vomiting in mothers with common cold during the pregnancy, while the occurrence of anemia was higher. The mean birth weight was somewhat larger, and is associated with a smaller proportion of low birthweight, though gestational age was somewhat shorter and the proportion of preterm birth was somewhat larger.

Table 4. Data of delivery outcomes in newborn infants born to mothers with common cold and without common cold (as referent), in addition with or without antifever therapy

\begin{tabular}{|c|c|c|c|c|c|c|c|c|c|c|c|c|c|c|}
\hline \multirow{4}{*}{$\begin{array}{l}\text { Variables } \\
\text { Continuous } \\
\end{array}$} & \multicolumn{4}{|c|}{ Pregnant women } & \multirow{3}{*}{\multicolumn{2}{|c|}{ Adjusted }} & \multirow{3}{*}{\multicolumn{2}{|c|}{$\begin{array}{c}\text { Common cold } \\
\text { with } \\
\text { antifever } \\
\text { therapy } \\
(\mathrm{N}=2,047) \\
\end{array}$}} & \multirow{3}{*}{\multicolumn{2}{|c|}{ Adjusted }} & \multirow{3}{*}{\multicolumn{2}{|c|}{$\begin{array}{l}\text { Common cold } \\
\text { without } \\
\text { antifever } \\
\text { therapy } \\
(\mathrm{N}=3,428)\end{array}$}} & \multirow{3}{*}{\multicolumn{2}{|c|}{ Adjusted }} \\
\hline & \multirow{2}{*}{\multicolumn{2}{|c|}{$\begin{array}{c}\begin{array}{c}\text { with } \\
\text { common cold }\end{array} \\
(N=5,475)\end{array}$}} & \multirow{2}{*}{\multicolumn{2}{|c|}{$\begin{array}{c}\begin{array}{c}\text { without } \\
\text { common cold }\end{array} \\
(\mathrm{N}=32,676)\end{array}$}} & & & & & & & & & & \\
\hline & & & & & & & & & & & & & & \\
\hline & Mean & S.D. & Mean & S.D. & $t$ & $p$ & Mean & S.D. & $\mathrm{t}$ & $p$ & Mean & S.D. & $\mathrm{t}$ & $p$ \\
\hline Gestational age, wk & 39.3 & 2.0 & 39.4 & 2.1 & -3.4 & 0.0008 & 39.3 & 2.0 & 1.8 & 0.08 & 39.3 & 2.0 & 2.5 & 0.01 \\
\hline Birth weight, g & 3305 & 487 & 3271 & 515 & -2.6 & 0.008 & 3303 & 488 & -1.9 & 0.06 & 3306 & 487 & -2.9 & 0.004 \\
\hline Categorical & No. & $\%$ & No. & $\%$ & POR & $95 \% \mathrm{Cl}$ & No. & $\%$ & POR & $95 \% \mathrm{Cl}$ & No. & $\%$ & POR & $95 \% \mathrm{Cl}$ \\
\hline Preterm birth & 539 & 9.8 & 2,957 & 9.1 & 1.2 & $1.1-1.3$ & 206 & 10.1 & 1.2 & $1.0-1.4$ & 333 & 9.7 & 1.1 & $1.0-1.3$ \\
\hline Postterm birth & 542 & 9.9 & 3,320 & 10.2 & 0.9 & $0.8-1.0$ & 201 & 9.8 & 1.0 & $0.8-1.1$ & 341 & 10.0 & 1.0 & $0.9-1.1$ \\
\hline Low birthweight & 231 & 4.2 & 1,936 & 5.9 & 0.8 & $0.7-0.9$ & 91 & 4.5 & 0.8 & $0.6-0.9$ & 140 & 4.1 & 0.7 & $0.6-0.9$ \\
\hline Large birthweight & 35 & 0.6 & 280 & 0.9 & 0.7 & $0.5-1.0$ & 11 & 0.5 & 0.6 & $0.3-1.1$ & 24 & 0.7 & 0.8 & $0.5-1.2$ \\
\hline
\end{tabular}


The strengths of HCCSCA can be explained by the large and population-based data set including 5,475 pregnant women with common cold from an ethnically homogeneous European (Caucasian) people in which pregnancy complications, in addition gestational age and birth weight were medically recorded and potential confounding factors were available for analysis. Of course, limitations of the data set need to be mentioned as well. The major weakness of our study is the unreliable diagnosis of reported common cold without the identification of microbial agents. Thus the differential diagnosis between common cold and acute infectious diseases of respiratory system, in addition between common cold and influenza was not based on scientific evidence. Response rate was $83 \%$. Only 200 non-respondent mothers were visited at home, because the ethics committee considered that this follow-up would be disturbing to the parents of all healthy children. However, the prevalence of maternal diseases including common cold did not show differences between respondent and nonrespondent families (5). Another limitation in our study is the lack of data regarding maternal smoking and alcohol drinking as confounder. Our previous validation study showed the low reliability of retrospective maternal self-reported information regarding smoking and alcohol drinking in the mothers of cases with congenital abnormalities (7), therefore these data were collected only in a minor part of the data set of the HCCSCA based on the home visit. Of 200 mothers, 38 (19\%) smoked and less than $1 \%$ drank alcohol regularly during pregnancy.

The major finding of the study is that common cold, the most frequent maternal disease during pregnancy (8) is not associated with a higher prevalence of pregnancy complications except anemia and the rate of preterm birth. The higher rate of anemia is in agreement with the lower intake of iron and folic acid by mothers with common cold and this health status may have a higher risk for common cold $(9,10)$. The lower proportion of some pregnancy complications (mainly threatened preterm birth and placental disorders) in pregnant women with common cold, and somewhat larger birth weight and smaller proportion of low birthweight in their newborn infants needs further studies. A better lifestyle due to the anxiety caused by common cold during pregnancy does not seem to be a reasonable hypothesis.

In conclusion, our findings indicate that common cold does not result in a clinically important risk for pregnancy complications and delivery outcomes including preterm birth.

\section{Acknowledgement}

This study was partly sponsored by a generous grant from Richter Gedeon Pharmaceuticals Ltd., Budapest, Hungary.

\section{REFERENCES}

1. Mäkelä MJ, Puhakka T, Ruuskanen O, Leinonen M, Saikku P, Kimpimäki M, Blomqvist S, Hyypiä T, Arstila P. Viruses and bacteria in the etiology of the common cold. J Clin Microbiol. 1998 Feb;36(2):539-42.

2. Heikkinen T, Järvinen A. The common cold. Lancet. 2003 Jan 4;361 (9351):51-9.

3. Czeizel AE, Rockenbauer M, Siffel C, Varga E. Description and mission evaluation of the Hungarian Case-Control Surveillance of Congenital Abnormalities, 1980-1996. Teratology. 2001 May;63(5):176-85.

4. Czeizel AE. First 25 years of the Hungarian Congenital Abnormality Registry. Teratology. 1997 May;55(5):299-305.

5. Czeizel AE, Petik D, Vargha P. Validation studies of drug exposures in pregnant women. Pharmacoepidemiol Drug Saf. 2003 Jul-Aug;12(5):409-16.

6. Puhó E, Métneki J, Czeizel AE. Maternal employment status and isolated orofacial clefts in Hungary. Cent Eur J Public Health. 2005 Sep;13(3):144-8.

7. Czeizel AE, Petik D, Puhó E. Smoking and alcohol drinking during pregnancy. The reliability of retrospective maternal self-reported information. Cent Eur J Publ Health. 2004 Dec;12(4):179-83.

8. Kudlová E. Life cycle approach to child and adolescent health.Cent Eur J Publ Health. 2004 Sep;12(3):166-70.

9. World Health Organization. The Prevalence of Anemia in Women: A Tabulation of Available Information. WHO/MCH/MSM. 92.2. 2nd ed. Geneva: WHO; 1992.

10. Beard JL. Iron biology in immune function, muscle metabolism and neuronal functioning. J Nutr. 2001 Feb;131(2S-2):568S-79S.

Received May 30, 2005

Received in revised form and accepted December 2, 2005 